(C) 2019 by the Arizona Board of Regents on behalf of the University of Arizona. This is an Open Access article, distributed under the terms of the Creative Commons Attribution-NonCommercial-ShareAlike licence (http://creativecommons.org/licenses/by-nc-sa/4.0/), which permits non-commercial re-use, distribution, and reproduction in any medium, provided the same Creative Commons licence is included and the original work is properly cited. The written permission of Cambridge University Press must be obtained for commercial re-use.

\title{
QUALITY DATING: A WELL-DEFINED PROTOCOL IMPLEMENTED AT ETH FOR HIGH-PRECISION 14C-DATES TESTED ON LATE GLACIAL WOOD
}

\author{
Adam Sookdeo ${ }^{1,2 *}$ (1) Bernd Kromer $^{3}$ • Ulf Büntgen, ${ }^{4,5}$ • Michael Friedrich ${ }^{3,7}$ • \\ Ronny Friedrich ${ }^{8}$ (1) Gerhard Helle ${ }^{9} \cdot$ Maren Pauly $^{9} \cdot$ Daniel Nievergelt $^{4}$ • \\ Frederick Reinig ${ }^{4}$ (D) Kerstin Treydte ${ }^{4} \cdot$ Hans-Arno Synal $^{1} \bullet$ Lukas Wacker $^{1}$ \\ ${ }^{1}$ ETH Zürich, Laboratory for Ion Beam Physics, Zurich, ZH, Switzerland \\ ${ }^{2}$ ETH Zürich, Carbon Cycle Biogeoscience, Zurich, ZH, Switzerland \\ ${ }^{3}$ Heidelberg University, Institute of Environmental Physics, Heidelberg, Baden-Württemberg, Germany \\ ${ }^{4}$ Swiss Federal Institute for Forest Snow and Landscape Research, Dendroecology, Birmensdorf, ZH, Switzerland \\ ${ }^{5}$ Cambridge University, Department of Geography, Cambridge, United Kingdom \\ ${ }^{6}$ Brno University of Technology, Global Change Research Institute CAS and Masaryk, Brno, Moravskoslezský, \\ Czech Republic \\ ${ }^{7}$ University of Hohenheim, Botany, Stuttgart, Baden-Württemberg, Germany \\ ${ }^{8}$ Reiss-Engelhorn-Museen, Curt-Engelhorn-Centre Archaeometry, Mannheim, Baden-Württemberg, Germany \\ ${ }^{9}$ GFZ, Section 5.2, Climate Dynamics and Landscape Evolution, Potsdam, Brandenburg, Germany
}

\begin{abstract}
Advances in accelerator mass spectrometry have resulted in an unprecedented amount of new highprecision radiocarbon $\left({ }^{14} \mathrm{C}\right.$ ) -dates, some of which will redefine the international ${ }^{14} \mathrm{C}$ calibration curves (IntCal and SHCal). Often these datasets are unaccompanied by detailed quality insurances in place at the laboratory, questioning whether the ${ }^{14} \mathrm{C}$ structure is real, a result of a laboratory variation or measurement-scatter. A handful of intercomparison studies attempt to elucidate laboratory offsets but may fail to identify measurement-scatter and are often financially constrained. Here we introduce a protocol, called Quality Dating, implemented at ETHZürich to ensure reproducible and accurate high-precision ${ }^{14} \mathrm{C}$-dates. The protocol highlights the importance of the continuous measurements and evaluation of blanks, standards, references and replicates. This protocol is tested on an absolutely dated German Late Glacial tree-ring chronology, part of which is intercompared with the Curt Engelhorn-Center for Archaeometry, Mannheim, Germany (CEZA). The combined dataset contains 170 highly resolved, highly precise ${ }^{14} \mathrm{C}$-dates that supplement three decadal dates spanning 280 cal. years in IntCal, and provides detailed ${ }^{14} \mathrm{C}$ structure for this interval.
\end{abstract}

KEYWORDS: high-precision radiocarbon, IntCal, MICADAS, Preboreal Pine chronology, radiocarbon dating.

\section{INTRODUCTION}

Radiocarbon $\left({ }^{14} \mathrm{C}\right)$ dating can be used to determine the age of an object or reconstruct past atmospheric and oceanic concentrations. While a calendrical age of a ${ }^{14} \mathrm{C}$-date(s) is determined through calibration (IntCal, SHCal), reconstructed concentrations are derived from a variety of archives. These ${ }^{14} \mathrm{C}$-archives, in turn, form the backbone of IntCal (Reimer et al 2013a) and SHCal (Hogg et al. 2013a); the touchstone for which are tree-ring chronologies. Tree rings can be dendrochronologically dated to within 1 year to $\sim 12 \mathrm{k}$ BP (Before Present years before 1950 AD; Friedrich et al. 2004) and are a direct measure of atmospheric ${ }^{14} \mathrm{C}$ (Becker 1993; Kromer and Becker 1993; Stuiver and Pearson 1993; Friedrich et al. 1999; Reimer et al. 2013b). An individual tree ring serves as means to reconstruct atmospheric ${ }^{14} \mathrm{C}$ with annual resolution. These annual ${ }^{14} \mathrm{C}$-dates are possible thanks to the relatively small sample-size $(\leq 10 \mathrm{mg})$ required by accelerator mass spectrometer (AMS). New annual or high resolution AMS ${ }^{14} \mathrm{C}$-dates help to establish "wiggles" and identify rapid increases in atmospheric in ${ }^{14} \mathrm{C}$.

\footnotetext{
*Corresponding author. Email: asookdeo@phys.ethz.ch.
} 
A wiggle can be the result of a change in ${ }^{14} \mathrm{C}$ production its distribution within the carbon cycle (Stuiver and Braziunas 1993), whereas year-to-year spikes originate solely from production changes (Miyake et al. 2012, 2013; Büntgen et al. 2018). Single-year increases have been discovered twice in annual tree-ring data (Miyake et al. 2012, 2013) and are speculated to be a product of solar flares (Usoskin et al. 2013). Longer-term production changes in ${ }^{14} \mathrm{C}$ are inversely related to solar activity, and millennial-scale variations are correlated with changes in the geomagnetic field (Stuiver and Braziunas 1993). ${ }^{14} \mathrm{C}$ dataset with such features (precise calendar ages, well-defined wiggles, and single year spikes) will improve ${ }^{14} \mathrm{C}$ calibration curves and thus reduced the uncertainty of calibrated ${ }^{14} \mathrm{C}$-dates but before such datasets are incorporated into IntCal or SHCal, they must be tested for their consistency and reproducibility (Reimer et al. 2013b).

Intercomparsions focus on the reproducibility of a set of unknowns and the determination of any laboratory offsets (Adolphi et al. 2013; Hogg et al. 2013b). These studies are often expensive and time consuming, thus not always feasible for every ${ }^{14} \mathrm{C}$ laboratory or every ${ }^{14} \mathrm{C}$ project. To identify internal issues, many laboratories have quality insurances in place but these are not always published, making it difficult to ascertain whether the ${ }^{14} \mathrm{C}$ structure in a dataset is real, a result of a laboratory variation or measurement-scatter.

Here we present ETH's protocol to ensure reliable, reproducible high-precision ${ }^{14} \mathrm{C}$ dates, which is called Quality Dating. As a case study, we applied the Quality Dating protocol to ${ }^{14} \mathrm{C}$ dates on Late Glacial wood from 12.16 to $11.88 \mathrm{kBP}$, where only three decadal dates presently exist in IntCal13 (Reimer et al. 2013a) and intercompared our results with data from the Curt-Engelhorn-Zentrum for Archaeometry (CEZA).

\section{METHOD}

\section{Dendrochronology}

Tree-ring width (TRW) measurements were taken from at least two radii of each sampled tree using a LINTAB measuring device with a precision of $0.01 \mathrm{~mm}$ and the software program TSAPWin (Rinn 1996). The TRW measurements were visually and statistically cross-dated using t-values and Gleichläufigkeit (Glk) indices (Baillie and Pilcher 1973) in TSAPWin. Chronologies were established and checked with Cofecha (Holmes 1983). Individual trees (BREI0232, COTT0418) were selected for ${ }^{14} \mathrm{C}$ dating by wood quality, length and positioning within the developed chronologies (Friedrich et al. 2004). Tree rings sampled spanned two to seven years dependent on the width of single-rings. The mean dendrochronological linkages from Preboreal Pine Chronology (PPC)-Cottbus (Cott) and PPC-Breitenthal (BREI) that has been remeasured since Friedrich et al. (2004) publication can be seen in Figure 1.

\section{Sample Preparation and Measurements}

A chemical blank, Phthalic Anhydride (PhA, SigmaAldrich, PN-320064-500 g), was used to detect contamination from the graphitization process and the MIni CArbon DAting System (MICADAS). Fossilized wood "Braunkohle" (BK, also known as brown coal is lignite from Reichwalde, Gemany) and kauri wood (KB, MIS 7, New Zealand) were used as process blanks. Standards were Oxalic acid II (OXII, NIST SRM 4990C) and Oxalic acid I (OXI, SRM 4990B). The reference, a 10-year block of kauri wood (TK121), is from 


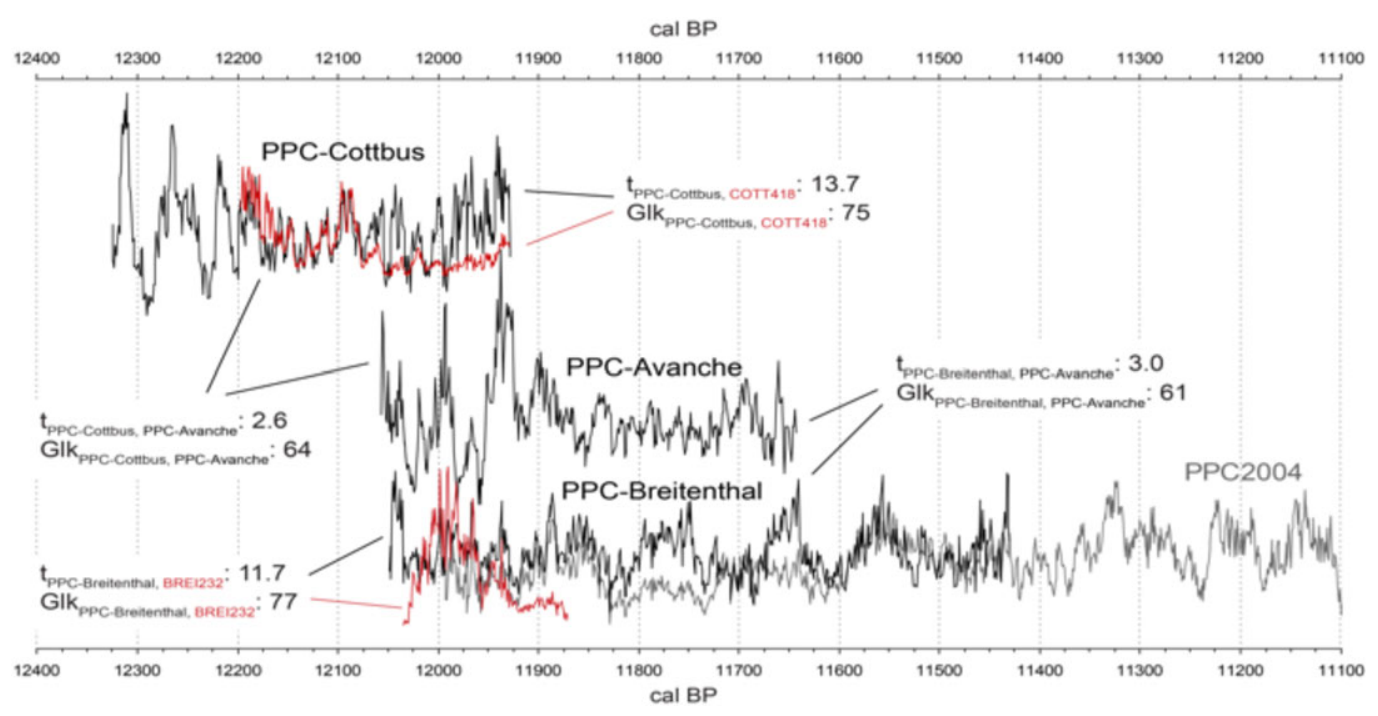

Figure 1 The t-value and Glk values for the dendrochronological linkage of PPC chronologies around $12 \mathrm{kBP}$. The mean tree rings widths are given that have been re-measured since Friedrich et al. (2004) publication.

the Younger Dryas (the period of interest for this study) and is dated to $10,968 \pm 21{ }^{14} \mathrm{C} \mathrm{yr}(1-\sigma$; Hogg et al. 2013b). The samples BREI0232 and COTT418 are pines (Pinus sylvestris L.) from the PPC and are part of a larger discovery in Breitenthal and Cottbus, Germany, which is discussed in detail by Friedrich et al. (2004).

Process blanks, reference material and samples were chemically treated to extract cellulose. Cellulose is a component of wood that has remained unchanged over time and can be used for an accurate ${ }^{14}$ C-date (Hoper et al. 1998; Brock et al. 2010; Sookdeo et al. 2017). Cellulose was extracted in batches of 56 (2 TK121, 2 BK, 2 KB and 50 samples) using a modified base-acid-base-acid-bleaching method outlined by Němec et al. (2010). The modified method involved an over-the-weekend base step at $60^{\circ} \mathrm{C}$ and step four was replaced with an acid rinse rather than letting the samples sit for an hour, which resulted in whiter cellulose than the method outlined by Nermec et al. (2010). The extracted cellulose was placed in a freeze dryer overnight. For each of the standards, blanks and samples $1 \mathrm{mg}$ of carbon were placed inside aluminum capsules $(4 \times 4 \times 11 \mathrm{~mm}$, Elementar $)$ and closed. These capsules were placed into an Elemental Analyzer (EA, Vario MICROcube, Elementar) sample holder.

Samples, standards and blanks were dropped into the heated chamber of an EA one at a time, where oxygen gas was fed in for $50 \mathrm{sec}$ to facilitate the combustion of carbon to carbon dioxide, which was captured in a zeolite trap. The estimated cross-contamination between capsules in an EA is less than $0.6 \%$ (Wacker et al. 2010a). Nevertheless, to limit cross-contamination, whenever a batch of standards, blanks, or samples were run, additional capsules containing analogues material (termed pre-conditions) were prepared. Two pre-conditions were used to clean the system when changing from one set of material to another: these were combusted in the EA, loaded onto the trap and then discarded. The graphitized materials were pressed into aluminum cathodes (Ionplus), organized, and placed in the sample holder (the magazine) of a MICADAS (Ionplus). 
One magazine contained seven standards, either four OXI or three OXII or vice versa, one PhA, four process-blank (two BK, two KB), two TK121 and 25 samples. Samples were bracketed by standards to detect any potential time-dependent variation. Magazines were measured on a MICADAS at the Laboratory of Ion Beam Physics, ETH-Zürich (Synal et al. 2007; Wacker et al. 2010b). Measurements times varied between two or three days or until the uncertainty on a sample's ${ }^{14} \mathrm{C}$-age was approximately 21 years $\left(200,000{ }^{14} \mathrm{C}\right.$ counts). Data reduction was carried out with the BATS program as described by Wacker et al. (2010c), in compliance with data processing for AMS measurements.

As an opportunity to further test the methodology used at ETH, 72 identical samples were sent to, prepared at and the ${ }^{14} \mathrm{C}$ age determined at CEZA on their MICADAS. These samples are given the identifier "MAMS."

The samples, process blanks and reference materials measured at CEZA were treated identically to extract cellulose. The applied cellulose method was a base (overnight; $4 \%$ $\mathrm{NaOH}$ )-acid (30 min; 4\% HCl)-base (30 min; 4\% NaOH)-bleaching (at least $60 \mathrm{~min}$; pH 3 $\mathrm{NaClO}_{2}$ ) with all steps undertaken at $60^{\circ} \mathrm{C}$. The bleaching was repeated until the material turned white, after which it was washed thoroughly with deionized water. Samples were dried in an oven at $80^{\circ} \mathrm{C}$ and approximately $1 \mathrm{mg}$ of carbon was placed in aluminum capsules (Elementar) and combusted in an EA (Vario MIRCOcube, Elementar). Samples were either graphitized on an in-house system or an AGE-3 (Ionplus). The custom graphitization system used a liquid-nitrogen-cooled trap in contrast to the zeolite trap of an AGE-3. Graphite was compressed into aluminum cathodes (Ionplus). In addition, to the 72 samples mentioned above, 23 and three samples from the PPC were measured at ETHZürich and CEZA, respectively.

\section{RESULT AND DISCUSSION}

\section{Blanks}

The distributions of 33 combustion blanks (PhA), and 164 process blanks (BK and KB) are compared in Figure 2. While a $\mathrm{PhA}$ blank is typically indistinguishable from a process blank, the mean $\mathrm{F}^{14} \mathrm{C}$ values differ $(\mathrm{p}<<0.05)$ with $0.00132 \pm 0.00005\left(1-\sigma ; 53.3 \mathrm{k}{ }^{14} \mathrm{C}\right.$ yr $)$ compared to $0.00164 \pm 0.00003 \mathrm{~F}^{14} \mathrm{C}\left(1-\sigma ; 51.7 \mathrm{k}{ }^{14} \mathrm{C} \mathrm{yr}\right)$, respectively. The more degraded fossilized wood (BK) is indistinguishable from the better preserved kauri wood (KB), though its cellulose yield was reduced by approx. $30 \%$.

The difference between the combustion and process blanks arises because the combustion blank is not subjected to the cellulose extraction treatment. The role of the PhA is to detect any potential contamination during graphitization and target preparation, but it is not used for data reduction as it tends to underestimate ${ }^{14} \mathrm{C}$ introduced during sample processing. Rather, the process blanks (Figure 2) are used for background correction with an uncertainty in $\mathrm{F}^{14} \mathrm{C}$ of 0.0004 (the uncertainty in a single blank measurement, corresponding to a background of $57,000{ }^{14} \mathrm{C} \mathrm{yr}$ ). The uncertainty determined for process blanks in a magazine is used for error propagation of samples. The background is calculated according to Stuiver and Polach (1977; 2- $\sigma$ limit).

To appropriately estimate ${ }^{14} \mathrm{C}$ background and variability, we suggest having at least four process blanks per 25 samples-the first step of our protocol. 


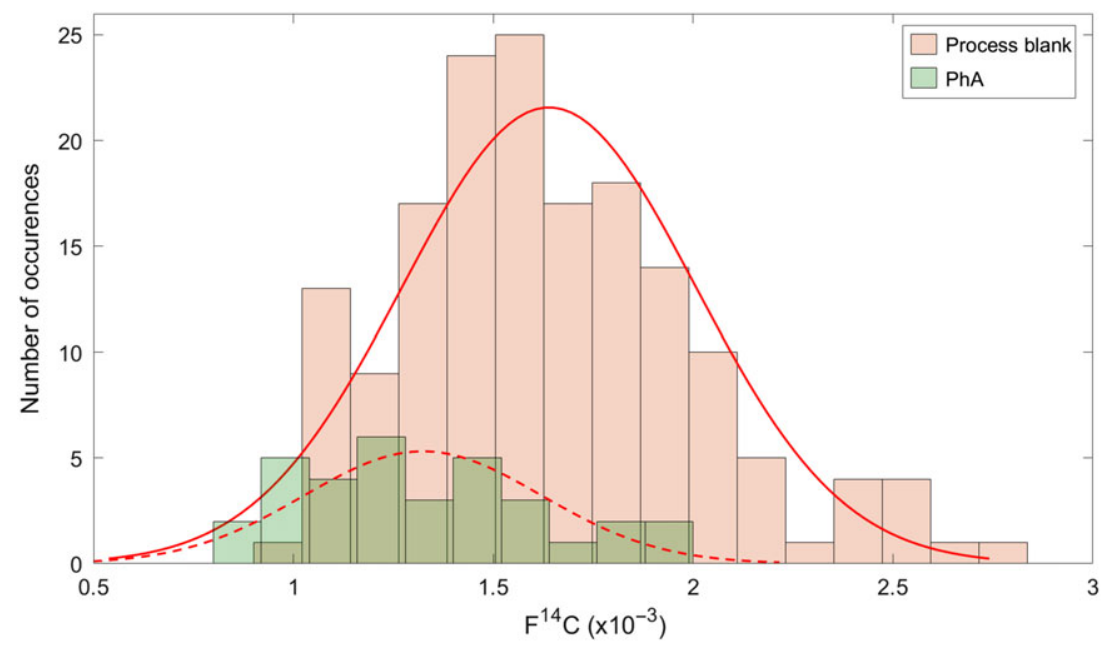

Figure 2 Distributions of $\mathrm{F}^{14} \mathrm{C}$ for 166 process blanks (Kauri and Brown coal wood, red) and 33 combustible blanks (PhA, green) measured at ETH-Zürich over 2 years are fitted with normal distributions (red lines).

\section{Standards}

Standards of OXII, OXI or another compound with a known ${ }^{14} \mathrm{C}$ concentration are used to determine the $\mathrm{F}^{14} \mathrm{C}$ value for a sample. The linearity of standard normalization in between months and years of measurements is rarely reported. Over the course of two years at ETH, a mixture of seven OXII and OXI per magazine measured at ETH is extremely consistent (Wacker et al. 2019). The mean $\mathrm{F}^{14} \mathrm{C}$ for 77 OXII normalized to OXI was 1.340119 $\pm 0.000184(1-\sigma)$, in good agreement with the consensus value of $1.34066 \pm 0.00043$ (1- $\sigma$; Mann 1983; Stuiver 1983). The strong reproducibility of our standards was not affected by different cation $\left({ }^{12} \mathrm{C}^{+}\right.$and $\left.{ }^{13} \mathrm{C}^{+}\right)$currents measured between magazines (Wacker et al. 2019). In addition, the uncertainties of the individual standards, as well as the samples, have a relative $1 \%$ added for the reproducibility of the analysis, including sample preparation. The additional uncertainty was estimated from the reproduction of the reference material and the intercomparison with Mannheim. While a drawback of having various standards in magazines can be time (if more are required) and cost (if new standards have to be ordered), determining the linearity of standard normalization is the second step of this protocol.

\section{Reference Material}

The results of reference material provided crucial information on whether sample preparations along with ${ }^{14} \mathrm{C}$ measurements are reproducible. TK121, a 10-year block of wood from the Towai chronology (Hogg et al. 2016) served as a reference for this study, as it has (1) been ${ }^{14} \mathrm{C}$ dated by five different laboratories-with a consensus age of $10,968 \pm 21{ }^{14} \mathrm{C}$ years $(1-\sigma$; Hogg et al. 2013b), (2) no large year-to-year variations (Hogg et al. 2016), and (3) a representative ${ }^{14} \mathrm{C}$ age and composition to the samples presented in this study. The TK121 measurements over the course of two years at ETH are given in Figure 3.

The mean ${ }^{14} \mathrm{C}$ age was determined to be $10,954 \pm 20 \mathrm{BP}(1-\sigma)$ with a standard error in the mean of \pm 2 years. A normalized $\chi^{2}$ red -test performed on TK121 yield a value of 0.72 . A significance 


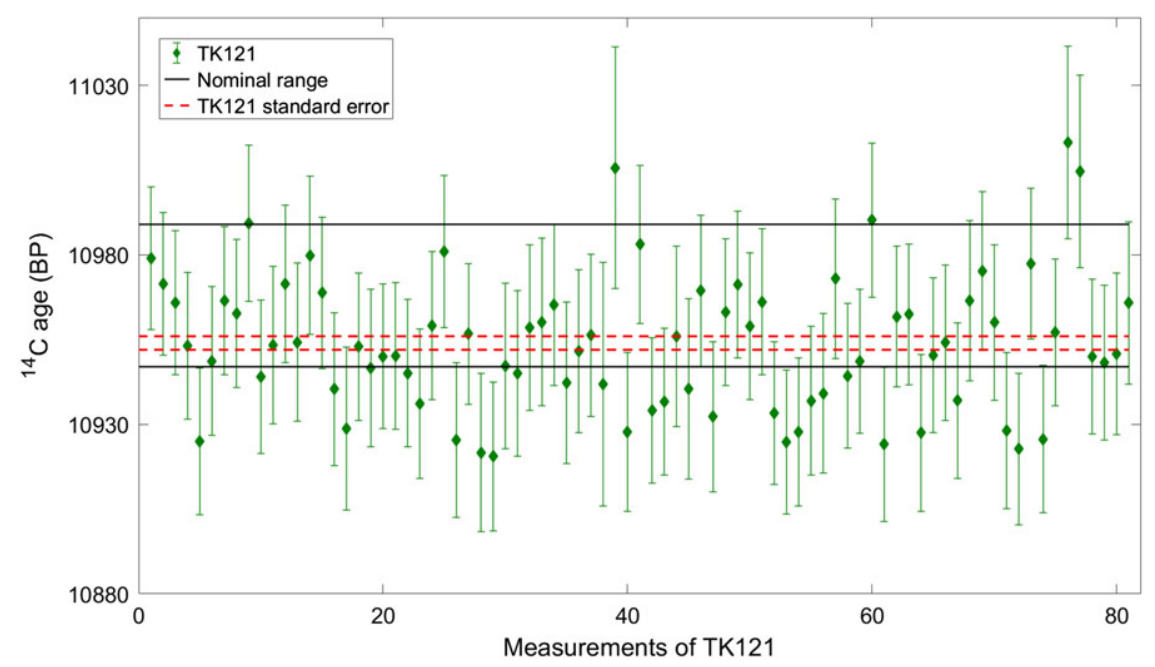

Figure $3{ }^{14} \mathrm{C}$ age for 81 reference samples (TK121, green) measured at ETH-Zürich with their mean value (1- $\sigma$ limits, red lines) and the nominal value (black, see Methods section).

level of 0.95 for a dataset of this size would result in $\chi^{2}$ red of 0.76 . Because our value is smaller it indicates our uncertainties are precise with a tendency to be conservatively overestimated. However, this could be the result of the well preserved nature of kauri wood, and not justifiable to reduce our ${ }^{14} \mathrm{C}$ uncertainties for other samples. Therefore, the uncertainties quoted here and on German Late Glacial wood are not reduced. Rather these uncertainties include contributions from the variability of the background $\left( \pm 0.0004\right.$ in $\left.\mathrm{F}^{14} \mathrm{C}\right)$, counting statistics of the seven standards (approx. 0.5\%), counting statistics of the sample (approx. $2 \%$ ) and $1 \%$ for the reproducibility of the analysis. The uncertainties for 81 TK121 are all within the $1-\sigma$ of Hogg et al. (2013b). Hence, the third step of our protocol is to measure two references per 25 unknowns.

\section{Intercomparison between CEZA and ETH-Zürich}

Intercomparisons serve a similar function to references or duplicates of unknowns with the added benefit of identifying laboratory offsets (Adolphi et al. 2013; Hogg et al. 2013b). As part of an ongoing project, Late-Glacial wood is being measured at ETH. Late-Glacial tree-rings measured at ETH generated structure (see Extension of the PPC) not visible in IntCal13. Futhermore, this structure is reflected in the 72 identical samples chemically extracted, graphitized and ${ }^{14} \mathrm{C}$ dated at CEZA (see Methods), which are in excellent agreement in a distribution of differences (Figure 4). The mean of this distribution was determined to be $-3 \pm 4{ }^{14} \mathrm{C}$ yr $(1-\sigma)$ with a $\chi_{\text {red }}^{2}$ of 1.06 .

This $\chi_{\text {red }}^{2}$ value is an indication that the calculated uncertainties in both laboratories were appropriately estimated, which is in contrast to our findings based on the references. While in principle the increased $\chi^{2}$ red of the replications compared to the reference material could be explained by a possible underestimation of uncertainties by CEZA, we think it is more likely due to the different state of preservation of the wood samples, thus the excellent agreement between CEZA and ETH validates the Quality Dating protocol implemented on Late Glacial wood. It is not realistic for all laboratories to be able to have the time and 
(a)
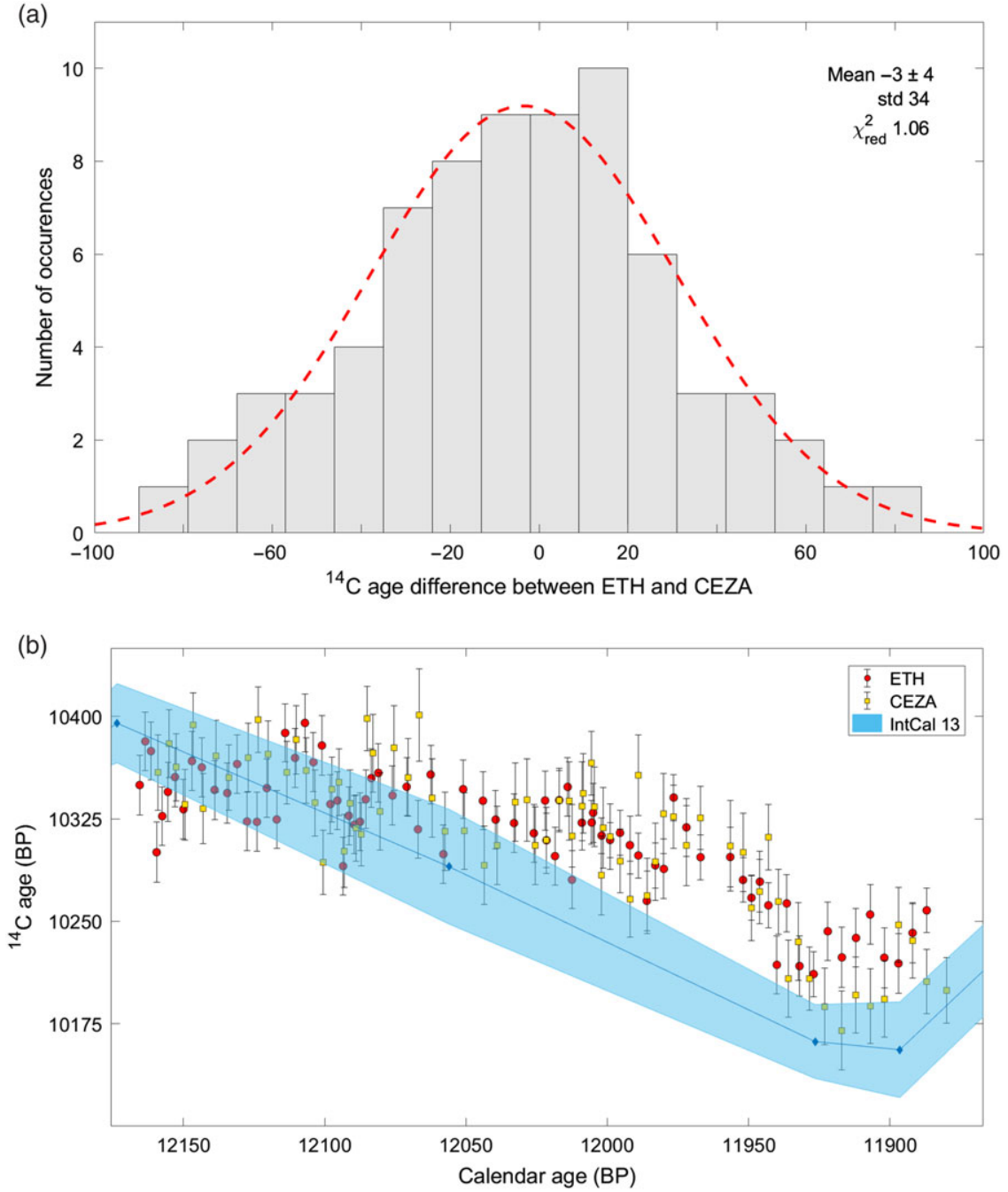

Figure 4 (a) Histogram of ${ }^{14} \mathrm{C}$ age differences for the same samples prepared and measured separately at ETH-Zürich and CEZA (grey), overlaid with a normal curve (red). (b) ${ }^{14} \mathrm{C}$ ages for dendrochronologically dated tree rings of the PPC measured at ETH-Zürich (red) and CEZA (yellow), plotted with the latest available calibration curve, IntCal13 (blue).

afford the work necessary for an intercomparison. Therefore, the fourth step of our protocol is to either have an intercomparison (ideally) or measure at least every fifth unknown in duplicates.

\section{Extension of the ${ }^{14} \mathrm{C}$ PPC Record}

The oldest part of world's longest absolute chronology, the PPC, has merely three decadal ${ }^{14} \mathrm{C}$-dates covering a period between 12,160 to 11,880 cal BP in IntCal13 (Reimer et al. 2013a). Together with the CEZA we introduce 170 high-precision ${ }^{14} \mathrm{C}$-dates that fill this period with high temporal resolution and structure (Figure $4 \mathrm{~b}$ ). The ${ }^{14} \mathrm{C}$ record starts with 
a plateau at 12.16 cal kBP lasting over 200 cal. years - not visible in IntCal13 (Reimer et al. 2013a). This plateau is structured with two small visible ${ }^{14} \mathrm{C}$ wiggles, before it is truncated by a $110{ }^{14} \mathrm{C}$ yr $\left(13 \%\right.$ o in $\left.\Delta^{14} \mathrm{C}\right)$ change within 40 calendar years, that again is not evident in the decadal measurements within IntCal13 (Figure 4b). The excellent agreement with CEZA shows that the structure introduced for this period is neither a result of large measurementscatter nor laboratory offsets. This extension of the PPC will be submitted to the next iteration of IntCal.

\section{CONCLUSION}

Advances in AMS measurements have led to a rapid increase of high precision, highly resolved ${ }^{14} \mathrm{C}$ dates that are not always accompanied by discussion of Quality Assurance. The Quality dating protocols presented here ensure reproducible, accurate and precise ${ }^{14} \mathrm{C}$-dates by

- having samples accompanied with process blanks rather than combustible blanks,

- running multiple standards of varying ${ }^{14} \mathrm{C}$ concentrations,

- continual measurements of references that are comparable in age and composition to the samples, and

- $\quad$ replication of measurement, ideally by another laboratory.

These requirements ensure proper background correction, robust standard normalization and reproducible results. However, this protocol is by no means the only way to ensure highprecision ${ }^{14} \mathrm{C}$-dates and we hope that other ${ }^{14} \mathrm{C}$ laboratories will publish their own protocols to ensure quality dating in the near future.

\section{ACKNOWLEDGMENTS}

The research was funded by the D-A-CH Lead-Agency agreement of the Swiss National Science Foundation (SNF 200021L-157187) and the German Research Foundation (DFG, Kr726/10-1). We thank Dr. John Southon and the two reviewers for their critical input that helped improve this manuscript, as well as Dr. Alan Hogg and Dr. Johnathan Palmer for supplying kauri blanks, and references.

\section{SUPPLEMENTARY MATERIAL}

To view supplementary material for this article, please visit https://doi.org/10.1017/RDC.2019.132

\section{REFERENCES}

Adolphi F, Güttler D, Wacker L, Skog G, Muscheler R. 2013. Intercomparison of ${ }^{14} \mathrm{C}$ dating of wood samples at Lund University and ETH-Zurich AMS facilities: extraction, graphitization, and measurement. Radiocarbon 55(2):391-400.

Baillie MG, Pilcher JR. 1973. A simple crossdating program for tree-ring research. Tree-Ring Bulletin 33:7-14.

Becker B. 1993. An 11,000-year German oak and pine dendrochronology for radiocarbon calibration. Radiocarbon 35(1):201-213.
Brock F, Higham T, Ditchfield P, Bronk Ramsey C. 2010. Current pretreatment methods for AMS radiocarbon dating at the Oxford Radiocarbon Accelerator Unit (ORAU). Radiocarbon 52(1): 103-112.

Büntgen U, Wacker L, Galván JD, Arnold S, Arseneault D, Baillie M, Beer J, Bernabei M, Bleicher N, Boswijk G, et al. 2018. Tree rings reveal globally coherent signature of cosmogenic radiocarbon events in 774 and 993 CE. Nature Communications 9:3605-3611. 
Friedrich M, Kromer B, Spurk M, Hofmann J, Kaiser KF. 1999 Paleo-environment and radiocarbon calibration as derived from Lateglacial/ Early Holocene tree-ring chronologies. Quaternary International 61(1):27-39.

Friedrich M, Remmele S, Kromer B, Hofmann J, Spurk M, Kaiser KF, Orcel C, Küppers M. 2004. The 12,460-year Hohenheim oak and pine tree-ring chronology from central Europe-a unique annual record for radiocarbon calibration and paleoenvironment reconstructions. Radiocarbon 46(3):1111-1122.

Hogg AG, Hua Q, Blackwell PG, Niu M, Buck CE, Guilderson TP, Heaton TJ, Palmer JG, Reimer PJ, Reimer RW, Turney CSM, Zimmerman SRH. 2013a. SHCal13 Southern Hemisphere calibration, 0-50,000 years cal BP. Radiocarbon 55:1889-1903.

Hogg A, Turney C, Palmer J, Southon J, Kromer B, Bronk Ramsey C, Boswijk G, Fenwick P, Noronha A, Staff R, Friedrich M. 2013b. The New Zealand kauri (Agathis australis) research project: a radiocarbon dating intercomparison of Younger Dryas wood and implications for IntCal13. Radiocarbon 55(4):2035-2048.

Hogg A, Southon J, Turney C, Palmer J, Bronk Ramsey C, Fenwick P, Boswijk G, Friedrich M, Helle G, Hughen K, Jones R, Kromer B, Noronha A, Reynard L, Staff R, Wacker L. 2016. Punctuated shutdown of Atlantic Meridional Overturning Circulation during Greenland Stadial 1. Scientific Reports 6: 25902.

Holmes RL. 1983. Program COFECHA user's manual. Laboratory of Tree-Ring Research, The University of Arizona, Tucson.

Hoper ST, McCormac FG, Hogg AG, Higham TFG, Head MJ. 1998. Evaluation of wood pretreatments on oak and cedar. Radiocarbon 40(1):45-50.

Kromer B, Becker B. 1993. German oak and pine ${ }^{14} \mathrm{C}$ calibration, 7200-9439 BC. Radiocarbon 35(1): 125-135.

Mann WB. 1983. An international reference material for radiocarbon dating. Radiocarbon 25: 519-527.

Miyake F, Nagaya K, Masuda K, Nakamura T. 2012. A signature of cosmic-ray increase in AD 774-775 from tree rings in Japan. Nature 486: 240-245

Miyake F, Masuda K, Nakamura T. 2013. Another rapid event in the carbon-14 content of tree rings. Nature Communications 4:1748-1751.

Reimer PJ, Bard E, Bayliss A, Beck JW, Blackwell PG, Bronk Ramsey C, Grootes PM, Guilderson TP, Haflidason H, Hajdas I, Hatté C, Heaton TJ, Hoffmann DL, Hogg AG, Hughen KA, Kaiser KF, Kromer B, Manning SW, Niu M, Reimer RW, Richards DA, Scott EM, Southon JR, Staff RA, Turney CSM, van der Plicht J. 2013a. IntCal13 and Marine13 radiocarbon age calibration curves 0-50,000 years cal BP. Radiocarbon 55(4):1869-1887.

Reimer PJ, Bard E, Bayliss A, Beck JW, Blackwell PG, Ramsey CB, Brown DM, Buck CE, Edwards RL, Friedrich M, Grootes PM, Guilderson TP, Haflidason H, Hajdas I, Hatté C, Heaton TJ, Hogg AG, Hughen KA, Kaiser KF, Kromer B, Manning SW, Niu M, Reimer RW, Richards DA, Scott EM, Southon JR, Turney CSM, van der Plicht J. 2013b. Selection and treatment of data for radiocarbon calibration: an update to the International Calibration (IntCal) criteria. Radiocarbon 55(4):1923-45.

Rinn F. 1996. Tsap V 3.6 Reference manual: computer program for tree-ring analysis and presentation. Rinntech, Heidelberg.

Sookdeo A, Wacker L, Fahrni S, McIntyre CP, Friedrich M, Reinig F, Nievergelt D, Tegel W, Kromer B, Büntgen U. 2017. Speed dating: a rapid way to determine the radiocarbon age of wood by EA-AMS. Radiocarbon 59:933-939.

Stuiver M. 1983. International agreements and the use of the new oxalic-acid standard. Radiocarbon 25:793-795.

Stuiver M, Polach H. 1977. Discussion: Reporting of ${ }^{14} \mathrm{C}$ data. Radiocarbon 19(3):355-363.

Stuiver M, Pearson GW. 1993. High-precision bidecadal calibration of the radiocarbon time scale, AD 1950-500 BC and 2500-6000 BC. Radiocarbon 35(1):1-23.

Stuiver M, Braziunas TF. 1993. Sun, ocean, climate and atmospheric ${ }^{14} \mathrm{CO}_{2}$ : an evaluation of causal and spectral relationships. The Holocene 3:289-305.

Synal H-A, Stocker M, Suter M. 2007. MICADAS: a new compact radiocarbon AMS system. Nuclear Instruments and Methods in Physics Research B 259(1):7-13.

Usoskin I, Kromer B, Ludlow F, Beer J, Friedrich M, Kovaltsov G, Solanki S, Wacker L. 2013. The AD775 cosmic event revisited: the Sun is to blame. Astronomy \& Astrophysics 552:L3.

Wacker L, Němec M, Bourquin J. 2010a. A revolutionary graphitisation system: fully automated, compact and simple. Nuclear Instruments and Methods in Physics Research B 268(7):931-934.

Wacker L, Bonani G, Friedrich M, Hajdas I, Kromer B, Němec M, Ruff M, Suter M, Synal H-A, Vockenhuber C. 2010b. MICADAS: routine and high-precision radiocarbon dating. Radiocarbon 52(3):252-262.

Wacker L, Christl M, Synal H-A. 2010c. Bats: a new tool for AMS data reduction. Nuclear Instruments and Methods in Physics Research B 268(7):976-979.

Wacker L, Bollhalder S, Sookdeo A, Synal H-A. 2019. Re-evaluation of the new Oxalic Acid standard with AMS. Nuclear Instruments and Methods in Physics Research B 455:178-180. 